\title{
Modulación de la respuesta inmune durante la infección por virus distemper canino: implicancias terapéuticas y en el desarrollo de vacunas
}

\author{
Modulation of immune response during canine distemper virus infection: \\ therapeutic and vaccine development implications \\ PF Céspedes*, P Cruz, CO Navarro \\ Facultad de Ciencias Veterinarias y Pecuarias, Laboratorio de Virología Animal, Universidad de Chile, Santiago, Chile.
}

\begin{abstract}
SUMMARY
Canine distemper virus (CDV) infection is the main infectious cause of mortality in canines and exotic animals worldwide, and also threatens several endangered species such as the giant panda and big felids. The CDV blocks interferon and cytokines signaling pathways through massive infection of peripheral mononuclear cells and lymphocytes, which decreases B and T cell proliferation and causes $\mathrm{CD} 4{ }^{+} \mathrm{Th} 1$ depletion. These events explain the severe and long lasting immunosuppression that characterizes CDV infection, which leads to a multisystemic disease with subsequent deleterious opportunistic infections. Complex events such as cell dysfunction caused directly by virus replication or exaggerated immune response triggered by infected cells, contribute to the establishment of diverse and complex neurologic diseases throughout the course of the disease. Considering that several species are affected and that CDV infection has a high morbidity and mortality, the present review highlights the relevance of designing safer vaccines, capable of both inducing strategic immunity and preventing CNS pathology. Additionally, in order to better understand the diverse and dynamic mechanisms involved in the disruption of the adaptive immune response, as well as immunity induction during viral infection and vaccination, this review addresses the role of dendritic cells (DC) during CDV infection. Furthermore, we will discuss how DC-based therapies could improve the outcome of these patients in terms of survival and prevention of associated sequels.
\end{abstract}

Palabras clave: respuesta inmune Th1, respuesta inmune Th17, virus distemper canino, células dendríticas.

Key words: Th1 immune response, Th17 immune response, canine distemper virus, dendritic cells.

\section{INTRODUCCIÓN}

En 1905 Henri Carré descubrió el virus distemper canino (VDC), causante de la enfermedad multisistémica más difundida, contagiosa y letal de cánidos y otras nueve familias de mamíferos (Mustelidae, Procyonidae, Ursidae, Viverridae, Hyaenidae, Phocidae y Felidae), llegando a comprometer drásticamente la conservación de especies amenazadas debido a su altísima letalidad (Pardo y col 2005). Este virus pertenece al orden Mononegavirales, a la familia Paramyxoviridae y al género Morbillivirus, posee envoltura y un tamaño entre 150 a $300 \mathrm{~nm}$ de diámetro (Summers y Appel 1994). Su genoma está constituido por ácido ribonucleico (ARN) no segmentado, de hebra simple y sentido de codificación negativo, formado por aproximadamente $15,7 \mathrm{~kb}$ que incluyen 6 genes organizados en unidades transcripcionales separadas y no traslapadas. En dirección 5'- 3' codifica 7 proteínas: la proteína de la nucleocápside (gen $\mathrm{N}$; de 1,5 kb), la fosfoproteína (gen P; que con un largo total de $1,5 \mathrm{~kb}$ codifica en las primeras 500 a 1.000 bases de su extremo 5' el gen $\mathrm{C}$ y gen V, de las proteínas $\mathrm{C}$ y $\mathrm{V}$, respectivamente), la proteína de la

Aceptado: 20.01.2010.

* Avda. Santa Rosa 11735, La Pintana, Santiago, Chile; pablocesdon@ gmail.com. matriz (gen M; de $1 \mathrm{~kb}$ ), la proteína de fusión (gen F; de $1,9 \mathrm{~kb}$ ), la hemaglutinina (gen $\mathrm{H}$; de $1,8 \mathrm{~kb}$ ) y la polimerasa grande (gen L; de 6,5 kb) (Sidhu y col 1993). Las proteínas estructurales corresponden a la proteína de matriz, de la nucleocápside, la polimerasa, la fosfoproteína y las glicoproteínas de envoltura, hemaglutinina y de fusión. Estas últimas son responsables del reconocimiento e ingreso del virus a la célula blanco, siendo el principal objetivo de los anticuerpos neutralizantes sintetizados por el sistema inmune del hospedero (Summers y Appel 1994). El ARN viral se encuentra empaquetado en la nucleocápside $y$, una vez dentro del citoplasma, funciona junto con la polimerasa viral y su cofactor, la fosfoproteína, como un complejo ribonucleoproteico que sintetiza ARN mensajero cubierto y poliadenilado, que mediante transcripción y replicación secuencial genera un antigenoma de largo completo esencial para la replicación viral (von Messling y col 2001). Pese a ser un virus envuelto muy sensible al medio ambiente, su constante eliminación a través de todo tipo de secreciones, exudados y fluidos corporales a partir del séptimo día postinfección, y su alta infectividad, permiten que se disemine rápidamente en el ecosistema gracias a la existencia de animales infectados que eliminan el virus antes de manifestar signos asociados a la virosis (Summers y Appel 1994). La naturaleza de la enfermedad es variable y su curso depende en gran medida de las complejas interacciones entre las características biológicas del 
virus (atenuación, tropismo y polimorfismo genético) y el sistema inmune del hospedero (grado de madurez, refuerzo, especificidad y eficiencia) siendo este último uno de los principales factores en determinar el curso, consecuencias y letalidad de la infección (Bonami y col 2007).

\section{PATOGENIA: INTERACCIONES TEMPRANAS CON EL SISTEMA INMUNE}

Las principales vías de ingreso del virus son la aerógena ocular-respiratoria y oral, a través de aerosoles y fómites, por medio de los cuales alcanza superficies mucosas donde establece la primera interacción con el sistema inmune del hospedero mediante la infección temprana de linfocitos locales y células mononucleares CD150+ (von Messling y col 2004, von Messling y col 2005). En este punto el virus despliega una serie de mecanismos rápidos que permiten neutralizar y evadir la respuesta inmune antiviral innata y adaptativa: (a) utilización de células del sistema inmune como vehículo de transporte a los nódulos linfáticos regionales, (b) replicación deletérea en subpoblaciones de linfocitos entre el primer y tercer día postinfección (PI), (c) establecimiento de la viremia primaria asociada a leucocitos, (d) replicación masiva en órganos linfoides con agotamiento selectivo de la subpoblación Th1 y (e) establecimiento del cuadro multisistémico al séptimo día PI (von Messling y col 2004).

La infección de linfocitos es dependiente de la hemaglutinina viral, glicoproteína de la envoltura lipídica que reconoce y se une al receptor linfocitario CD150/SLAM (Signaling Lymphocyte Activation Molecule) (von Messling y col 2001, Tatsuo y col 2001). El receptor CD150 se expresa de forma diferencial en distintas poblaciones celulares, siendo constitutiva en células hematopoyéticas e inducible en linfocitos T efectores y células plasmáticas (Cocks y col 1995, Sidorenko y Clark 2003). La amplia distribución de este receptor en poblaciones linfocitarias activas explica el exquisito linfotropismo del virus y la relevancia de la hemaglutinina en la virulencia y citopatogenicidad de VDC y otros Morbillivirus, siendo la unión de estas dos moléculas un evento clave en la infección de diversos tipos celulares y el determinante del tropismo de cada cepa viral (von Messling y col 2003, Vandevelde y Zurbriggen 2005).

Luego de infectar células inmunes, el virus asegura la síntesis del antigenoma (ARNm) y una replicación intracitoplasmática efectiva formando un complejo ribonucleoproteico, que evita el reconocimiento de intermediarios de ARN doble hebra por parte de TLR-3 (Toll Like Receptor-3) y, de esta forma, inhibe las vías de activación del factor de transcripción NF-кB (Nuclear Factor-Kappa B) responsable de activar la expresión de citoquinas proinflamatorias, quimioquinas, moléculas de adhesión y receptores inmunológicos (Curran y Kolakofsky 2000). En este punto, la patogénesis es influenciada adicionalmente por 2 productos generados en el ciclo replicativo viral, ambos derivados del gen $\mathrm{P}$ : las proteínas V y C (von Messling y col 2006). La primera actúa inhibiendo las vías de señalización de interferón y citoquinas aboliendo la señalización JAK (Janus Kinase)/ STAT (Signal Transducer and Activator of Transcription), marcando STAT1, 2 o 4 para su degradación proteosomal e interfiriendo con su activación dependiente de fosforilación mediada por el complejo JAK-receptor de citoquina (figura 1). Esto último se traduce en bajos niveles de transcripción y expresión de proteínas antivirales, citoquinas proinflamatorias (TNF- $\alpha$ e IL-6), citoquinas Th1 y Th2 específicas (IL-2 e IL-4, respectivamente) e interferones de la clase I (IFN $\alpha$ y $\beta$ ), siendo de esta forma un determinante de virulencia esencial en la invasión del hospedero (von Messling y col 2006). Este fenómeno explica la inhibición de la secreción de interferón gamma (IFN $\gamma$ ) en linfocitos Th1 y células natural killer (NK) y, consecuentemente, la interferencia de la respuesta inmune Th1 antiviral (Sidorenko y Clark 2003, von Messling y col 2005). La proteína C corresponde a un factor de infectividad que asegura el ensamble y liberación de partículas virales estables, sustentando fases tardías del cuadro multisistémico (von Messling y col 2006). Adicionalmente, la nucleoproteína viral se une como factor soluble al receptor CD32 (FcyRII) de linfocitos $\mathrm{B}$, desencadenando eventos que determinan una disminución temprana de su actividad proliferativa (Kerdiles y col 2006, von Messling y col 2006).

Estos fenómenos permiten que el virus utilice células inmunes para viajar a órganos linfáticos secundarios como pulpa blanca del bazo, nódulos linfáticos y tejido linfoide asociado a mucosas (tonsilas y placas de Peyer) que corresponden a los sitios de replicación preferencial antes del establecimiento de la viremia secundaria (von Messling y col 2004). En dichos tejidos el virus, a través de la unión a CD150, ejerce un efecto deletéreo sobre la respuesta inmune adaptativa antiviral, caracterizado por el agotamiento selectivo de linfocitos CD4 ${ }^{+}$Th1 mediante un proceso apoptótico (Schobesberger y col 2005, Pillet y von Messling 2009) afectando adicionalmente la actividad proliferativa de células $\mathrm{B}$ y $\mathrm{T} \mathrm{CD} 8^{+}$involucradas en la respuesta Th1 durante las primeras 72 horas PI (Sidorenko y Clark 2003, von Messling y col 2004, Suter y col 2005, Beineke y col 2009). La infección de tonsilas y placas de Peyer ha sido sugerida como uno de los eventos claves en el compromiso de la respuesta inmune de mucosas (Th2) mediada por IgA, facilitando el ingreso de patógenos desde las barreras epiteliales y las infecciones oportunistas (von Messling y col 2004). Todos estos mecanismos explican la severa leucopenia descrita entre el primer y séptimo día postinfección, con una disminución de hasta el $80 \%$ de las células mononucleares periféricas, y un alto porcentaje de linfocitos T y B infectados (40-60\%) (Rudd y col 2006). Sólo unos pocos monocitos/macrófagos expresan antígenos virales, lo que se relaciona directamente con su limitada expresión de CD150 (Cocks y col 1995). 


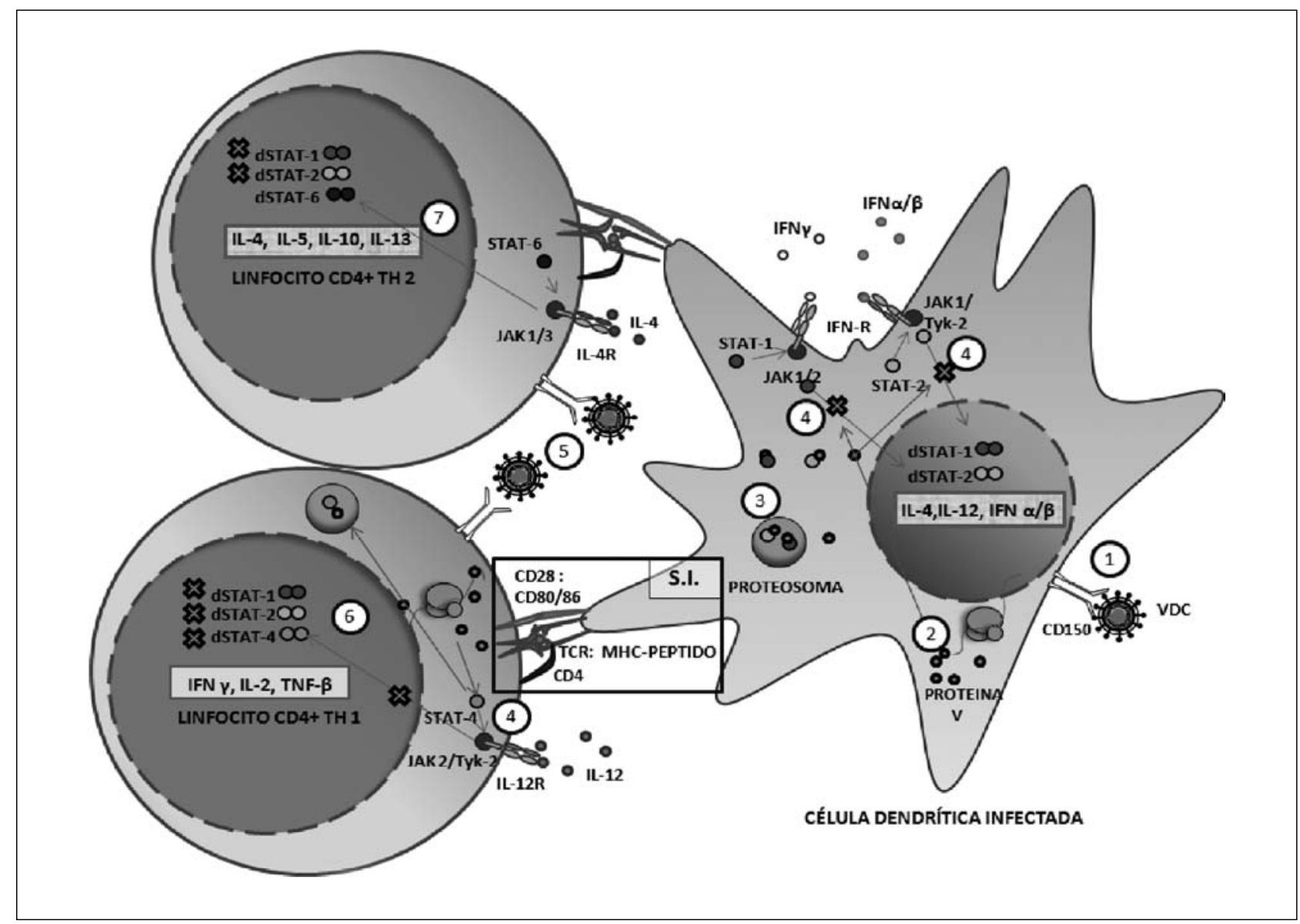

Figura 1. Modulación de la respuesta inmune por VDC. Eventos secuenciales desarrollados durante la infección de células mononucleares durante las primeras horas PI. 1) Reconocimiento de CD150 por la hemaglutinina viral e infección de CDs. 2) síntesis de proteínas estructurales y mediadores solubles del virus. Interferencia con la vía de señalización de citoquinas e interferones por parte de la proteína $\mathrm{V}$, a través de la degradación de STAT 1/2/4 (3) o la inhibición de su activación por enzimas de la familia JAK (4). (5) La inhibición de la fosforilación de STAT evita su dimerización (dSTAT-1/2/4) y consecuente traslocación al núcleo para unirse a los promotores de los genes de citoquinas y proteínas antivirales (destacadas en rojo). 6) Sinapsis infecciosa, el virus aprovecha el establecimiento de una sinapsis inmunológica (S.I.) para infectar linfocitos vírgenes, en los que despliega los mismos mecanismos para interrumpir su activación, proliferación, maduración y comunicación paracrina con otras células del sistema inmune. En linfocitos Th2 no se inhibe la vía de señalización de IL-4/JAK-1 o 3/STAT-6 (7).

Immune response modulation by CDV. Sequential events developed along the infection of mononuclear cells during the first hours postinfection (PI) 1) DCs infection through CD150 recognition by viral hemagglutinin. 2) Synthesis of viral structural and soluble proteins involved in immune response suppression. Disruption of cytokines and interferon signaling pathways mediated by viral V protein through degradation of STAT $1 / 2 / 4$ (3) or inhibition of their activation mediated by JAK family kinases (4). 5) Inhibition of STAT phosphorylation conduces to its reduced dimerization and consequent nuclear translocation and binding to promoters controlling cytokine and antiviral protein gene expression (highlighted in red). 6) Infectious synapse theory, CDV take advantage of immune synapse (S.I.) assembly to infect naïve T lymphocytes, where deploy similar mechanisms to disrupt activation, proliferation, maturation and paracrine cross-talk with other immune cells. 7) IL-4/JAK-1 or 3/STAT-6 signaling pathway is not inhibited in Th2 lymphocytes.

La rápida y masiva replicación viral en linfocitos prepara la invasión sistémica a través de la viremia secundaria asociada a células, que se caracteriza por altos títulos virales y el inicio del cuadro clínico. En este curso de la virosis, el sulfato de heparina presente en la superficie de células epiteliales y no inmunes actúa como receptor para la hemaglutinina, sustentando de esta manera la diseminación epiteliopantrópica propia de la fase más tardía de la infección (Rudd y col 2006, Zhao y col 2008), donde el comportamiento de la patología es altamente impredecible, describiéndose que aproximadamente un
$30 \%$ de los animales que desarrollan un cuadro multisistémico presentan algún grado de compromiso neurológico y, de ellos, un 10\% muere de encefalitis aguda (Rudd y col 2006). El establecimiento multisistémico y la viremia secundaria son etapas esenciales para que el virus asociado a células mononucleares y endoteliales infectadas alcance el Sistema Nervioso Central (SNC), a través del plexo coroideo y de los vasos sanguíneos cerebrales (Summers y Appel 1994, Vandevelde y Zurbriggen 2005). Sin embargo, no corresponde a la única vía de ingreso, pues algunas cepas durante la invasión masiva de la 
mucosa respiratoria y de sus células epiteliales infectan neuronas receptoras cercanas y de forma anterograda, a través de sinapsis neuronales, alcanzan nervio y bulbo olfatorio, lugares donde comienza el proceso patológico, diseminándose luego al resto del SNC (Rudd y col 2006). Alrededor del día 28 postinfección la enfermedad se acompaña con la presencia de virus libre en el fluido cerebroespinal, explicando la gran cantidad de focos de desmielinización ubicados bajo la piamadre en capas subyacentes del cuarto ventrículo, las cortezas cerebral y cerebelar (Vandevelde y Zurbriggen 2005).

\section{INMUNOPATOLOGÍA DEL CUADRO NEUROLÓGICO}

Los Morbillivirus sarampión y distemper producen desórdenes sistémicos similares en sus respectivos hospederos naturales, y aunque la frecuencia del compromiso del SNC difiere marcadamente $(0,1 \%$ versus $30 \%$, respectivamente), los procesos neuropatológicos que se desarrollan en el transcurso de la infección son similares (Summers y Appel 1994, Rudd y col 2006). Ambos virus causan encefalopatía aguda y leuco-, polio- o panencefalitis o encefalomielitis con desmielinización multifocal, y los cambios patológicos observados sugieren que la naturaleza del proceso involucra tanto eventos desencadenados directamente por la infección viral como por mecanismos inmunomediados o, eventualmente, de autoinmunidad (Lampert 1978, Krakowka y col 1985). Efectivamente, se ha demostrado citólisis inducida por virus en lesiones agudas no inflamatorias y un mecanismo inmunomediado en lesiones inflamatorias subagudas y crónicas (Frisk y col 1999, Moro y col 2003). Las lesiones no inflamatorias se caracterizan por la presencia de antígenos virales y niveles bajos de expresión del complejo principal de histocompatibilidad (MHC) clase II, mientras que en las lesiones crónicas existe una expresión reducida de antígenos y una fuerte sobreexpresión del MHC clase II con infiltración perivascular acumulativa de linfocitos $\mathrm{CD}^{+}$e infiltración parenquimatosa de células inmunes citotóxicas, evidencia que demuestra la naturaleza progresiva e inmunomediada de la patología neurológica (Baumgärtner y col 1989, Alldinger y col 1993, Müller y col 1995).

La llegada del virus al SNC a través de la barrera hematoencefálica ocurre en un escenario de severa inmunosupresión, y a pesar de la infección restrictiva de oligodendrocitos (menor al 10\%) se desarrolla un proceso temprano de desmielinización no inflamatoria, asociada a fenómenos derivados de la replicación viral en astrocitos y microglia, que corresponden a las poblaciones celulares responsables de mantener y facilitar la propagación viral en el SNC (Vandevelde 2004). En los escasos oligodendrocitos infectados, la transcripción viral interfiere con funciones especializadas causando un desequilibrio metabólico que conduce a una masiva depresión en la síntesis de mielina, caracterizada por la subexpresión de la proteína básica de mielina (PBM) y de la enzima cerebrósido-sulfotransferasa (Vandevelde y Zurbriggen 2005). Adicionalmente, se describe apoptosis y citólisis inducida por virus en la materia gris del cerebelo (Moro y col 2003). En esta fase inicial, la infección de macrófagos induce activación fagocítica local caracterizada por sobreexpresión del MHC clase II, de moléculas de adhesión (CD44) y por la producción de radicales libres, fenómenos responsables del daño sobre la vaina de mielina (Alldinger y col 1996). La exacerbación de la enfermedad se debe al aumento de expresión de citoquinas proinflamatorias, especialmente IL-1, IL-6 y factor de necrosis tumoral (TNF), sin existir un aumento compensatorio en la expresión de citoquinas antiinflamatorias (Frisk y col 1999, Gröne y col 2002, Markus y col 2002, Beineke y col 2008). El efecto detrimental de la infección sobre la subpoblación Th1 CD4+ es duradera, siendo más breve sobre la subpoblación Th2 y CD8 ${ }^{+} \mathrm{CD} 25^{+}$citotóxica. Esta última se recupera con prontitud e inicia una respuesta inmune antiviral en los cuadros agudos, infiltrando difusamente el parénquima del SNC donde ejerce citotoxicidad local que permite eliminar la infección del sistema entre los 14 y 21 días PI (Tipold y col 2005, Vandevelde y Zurbriggen 2005). Sin embargo, si la respuesta citotóxica es ineficiente se establece una infección persistente no citolítica que favorece la evasión de la respuesta inmune y la diseminación del virus en SNC, caracterizada por la expresión restrictiva de las proteínas de superficie y una infección masiva de neuronas que promueve lesiones crónicas inmunomediadas, progresivas y reincidentes (Tipold y col 2001, Vandevelde y Zurbriggen 2005). La población Th2 forma infiltrados perivasculares en SNC que responden al estímulo del MHC clase II expresado en células presentadoras de antígenos locales. Estos últimos son generados en el contexto del proceso inflamatorio propio de lesiones subagudas y crónicas.

Wünschmann y col (1999) describen 4 formas secuenciales de los eventos patológicos desarrollados en una escala temporal, caracterizados por diferencias marcadas en cuanto a sus características histo e inmunopatológicas: (1) lesiones agudas no inflamatorias carentes de desmielinización, (2) lesiones subagudas no inflamatorias, que marcan el inicio del daño sobre la vaina de mielina, (3) lesiones subagudas inflamatorias y (4) lesiones crónicas inflamatorias. En las lesiones no inflamatorias, la infección de astrocitos y microglia conduce a la sobreexpresión de CD44 y de su ligando, las metaloproteinasas de matriz (MMP). La interacción entre estas moléculas conduce a la apertura de la barrera hematoencefálica, que junto a la secreción de citoquinas promueve el inicio del proceso inflamatorio en las meninges y el parénquima del SNC (Alldinger y col 2006). En el transcurso de las lesiones inflamatorias, y en respuesta a la injuria propia de ellas, existe sobre-expresión de los inhibidores de metaloproteinasas (TIMP) e inhibición de la expresión de CD44, estableciendo un delicado equilibrio entre MMP-TIMP que 
logra disminuir la infiltración de células inflamatorias $\mathrm{CD} 44^{+}$ y la progresión del daño tisular (Miao y col 2003).

En momentos más tardíos, aproximadamente entre las 6 y 7 semanas postinfección comienza la recuperación de la subpoblación Th1 $\mathrm{CD}^{+}$y la formación de infiltrados perivasculares que promueven una fuerte respuesta inmune, caracterizada por la acumulación perivascular progresiva de esta población y la quimioatracción de monocitos y linfocitos efectores (citotóxicos y células plasmáticas). Todo esto conduce al establecimiento de un cuadro inflamatorio del SNC, potenciado por el acúmulo temprano de citoquinas proinflamatorias y el daño inicial del sistema, que comprende una desmielinización multifocal (placas subagudas y crónicas) acompañada de un infiltrado parenquimatoso progresivo de linfocitos citotóxicos $\mathrm{CD} 8^{+}$, que responde a la gran cantidad de citoquinas producidas por $\mathrm{CD}^{+} \mathrm{y}$ los antígenos presentados por macrófagos y células dendríticas (Wünschmann y col 1999). La desregulación de la respuesta inmune Th1 (con expresión dominante de IL-12, IL-2 e IFN- $\gamma$ ) que a su vez es potenciada por la secreción de anticuerpos contra las proteínas virales y los antígenos generados en las lesiones crónicas, incluyendo PBM, produce daño masivo a través de una respuesta inflamatoria y citotóxica exagerada (Gröne y col 2002, Vandevelde y Zurbriggen 2005). El reconocimiento de la porción Fc de anticuerpos anti-PBM por parte de células citotóxicas innatas y el sistema complemento produce daño colateral y directo sobre la oligodendroglia (Vandevelde y Zurbriggen 2005). De esta manera, se establece un efecto tsunami en el que la severa inmunosupresión sistémica que acompaña la infección del SNC permite la diseminación del virus, mientras la desregulación inmune facilita la producción incesante de citoquinas proinflamatorias en un parénquima que no es capaz de responder adecuadamente a ellas.

Debido a que en un comienzo el infiltrado perivascular sólo establece una respuesta Th2 que es incapaz de producir un clearance eficiente del virus, se promueve un fenómeno inflamatorio que daña el parénquima, facilitando la presentación de autoantígenos y la generación de autoanticuerpos. Así, luego de que se recupera la respuesta inmune mediada por $\mathrm{CD}^{+}{ }^{+} \mathrm{Th} 1$, se desencadenan eventos dirigidos a establecer una fuerte y masiva respuesta inmunitaria mediada por células $\mathrm{T}$ citotóxicas (linfocitos T CD8 ${ }^{+} \alpha \beta^{+}$o $\gamma \delta^{+}$) que acopladas a una fuerte reacción inflamatoria, conducen a un daño irremediable a la estructura tisular y función neurológica del hospedero (Tipold y col 1999).

\section{INMUNIDAD Y POLIMORFISMO GENÉTICO VIRAL}

El virus distemper se caracteriza por dañar la inmunidad innata y adaptativa desde momentos iniciales del cuadro infeccioso gracias a su elevado linfotropismo y capacidad de generar disrupción en funciones esenciales de células inmunes. Lo anterior se explica por complejas interacciones entre las proteínas virales y elementos propios de cada vía de señalización, que limita el desarrollo de una respuesta inmune antiviral Th1 efectiva y en perfecto equilibrio con una respuesta de mucosas Th2. Esta última cumple el rol fundamental de evitar infecciones productivas neutralizando agentes patógenos a nivel de superficies mucosas, mediante la secreción de anticuerpos IgA específicos. La respuesta Th1 permite eliminar infecciones ya establecidas utilizando linfocitos T citotóxicos $\mathrm{CD}^{+}$secretores de IFN $\gamma$ y células plasmáticas secretoras de anticuerpos neutralizantes de los isotipos IgG2a e IgG2c séricos. Considerando esta diferenciación funcional, una estrategia de vacunación óptima debe ser capaz de estimular ambas respuestas, de forma sólida y equilibrada. No obstante, se ha descrito que los virus atenuados utilizados actualmente en vacunas polivalentes poseen un linfotropismo y capacidad de inducir inmunosupresión residual, comprometiendo el balance de las respuestas inmunes mencionadas (Sereda y col 1999). Es más, la vacunación con virus atenuado afecta la actividad proliferativa de linfocitos $\mathrm{T}$ y neutrófilos favoreciendo la emergencia de infecciones oportunistas, lo que destaca la importancia de vacunar solamente animales sanos (Strasser y col 2003). Lo mencionado anteriormente demuestra que, a pesar de la capacidad que tiene el sistema inmune de responder adecuadamente a otro tipo de infecciones luego de los 6 meses de edad, 1) el desarrollo de un cuadro multisistémico en animales inmunizados mayores de 18 meses, 2) la incapacidad del sistema inmune de modular negativamente y controlar la población de linfocitos $\mathrm{T}$ autorreactivos responsables de la patología autoinmune en SNC y 3) la patología postvacunal descrita sugiere que para el caso de distempervirosis el sistema inmune no es completamente maduro, dependiendo en la mayoría de los casos de programas de vacunación bien diseñados para establecer una respuesta inmune sólida y duradera. Esto último tiene especial relevancia en aquellos animales más susceptibles, como individuos menores de 18 meses de edad y especies silvestres, en los que es recomendable recurrir a vacunas recombinantes que prescinden del patógeno y sólo utilizan algunos de sus antígenos para estimular adecuadamente al sistema inmune del hospedero. Esta última afirmación se sustenta en la evidencia de la capacidad del virus vacunal atenuado de revertir de manera fugaz su virulencia y causar encefalomielitis postvacunal letal en caninos y, de modo similar, un cuadro multisistémico de 90-100\% de morbilidad y letalidad en hurones de patas negras (Mustela putorius furo) (Summers y Appel 1994, von Messling y col 2003). Considerando estos antecedentes y utilizando virus viruela del canario o virus sarampión como vectores genéticos de los antígenos inmunodominantes de VDC, se ha demostrado la capacidad de estas vacunas recombinantes para estimular una rápida y sólida respuesta inmune tipo Th1, caracterizada por títulos de anticuerpos neutralizantes séricos hasta por 3 años (Larson y col 2006, Bronson y col 2007, Rouxel y col 2009). La 
primera de ellas posee la ventaja adicional de estar exenta de la interferencia por parte de los anticuerpos maternos, y al carecer de partículas de VDC, de la reversión de virulencia potencial y de la inmunosupresión residual presente en las vacunas polivalentes convencionales, permitiendo de esta forma vacunar animales desde las 4 semanas de edad (Larson y col 2007, Pardo y col 2007).

En animales correctamente inmunizados, la infección es incapaz de establecer un estado de inmunosupresión gracias a la sólida respuesta inmune antiviral desarrollada, que se caracteriza por la eliminación de cepas virulentas antes del establecimiento de la viremia secundaria, entre el tercer y quinto día PI (Tipold y col 2001). Actualmente, no existen vacunas capaces de estimular una respuesta inmune estratégica en el contexto de la distribución orgánica de los distintos elementos celulares y moleculares involucrados, tanto linfocitos $\mathrm{CD}^{+}{ }^{+}$Th 1 como Th 2 , y de las células efectoras y anticuerpos desarrollados. Si bien las vacunas polivalentes convencionales son capaces de estimular la secreción de anticuerpos neutralizantes tipo IgG1 e IgG2b, éstas sólo tienen una distribución sérica y un limitado poder de difusión a superficies mucosas. Adicionalmente, el limitado poder de protección de las vacunas polivalentes se explica por la variabilidad genética (polimorfismo) del virus, demostrándose una diferencia marcada en las características genéticas de las cepas vacunales y las causantes de brotes epidémicos en América del Norte, África, Europa, Japón y Argentina, tanto en poblaciones de caninos domésticos como silvestres (Martella y col 2002, Hirama y col 2004). Efectivamente, el análisis de polimorfismo genético ha demostrado diferencias significativas entre aislados clínicos y cepas utilizadas hace décadas como vacunas: SnyderHill, Onderstepoort, Rockborn, Convac y Lederle (Mochizuki y col 1999, Pardo y col 2005, Uema y col 2005, Lan y col 2006, Martella y col 2006, Calderón y col 2007). Dichos estudios han identificado 6 genotipos con una variación promedio de $10 \%$ en la composición del gen $\mathrm{H}$ (Zhao y col 2008), diferencia que determina la cantidad y ubicación de sitios de glicosilación de la hemaglutinina y, de esta forma, la fuerza de interacción con los receptores celulares, la extensión de la propagación viral y la virulencia de este Morbillivirus (von Messling y col 2001, Orlando y col 2008). Esta variabilidad genética determina cambios en los epítopos de la hemaglutinina y diferencias en la capacidad neutralizante de los anticuerpos derivados de la inmunización frente a otras cepas vacunales y diversos aislados de campo. En este contexto, los antígenos virales más relevantes en la inducción de inmunidad adaptativa no sólo corresponden a la hemaglutinina, sino que además a las proteínas de fusión y de la nucleocápside, siendo las dos primeras los principales objetivos de los anticuerpos neutralizantes debido a que la interacción con los receptores celulares depende exclusivamente de éstas (Zhao y col 2008).

El adecuado estímulo sobre el tejido linfoide asociado a mucosas, induce la proliferación de linfocitos $\mathrm{T}$ helper y citotóxicos junto con la secreción de anticuerpos $\operatorname{Ig} \mathrm{A}$ específicos, siendo estos últimos capaces de reconocer, unirse a las glicoproteínas virales e interferir con el reconocimiento de CD150 en los primeros momentos de la exposición al virus, evitando su diseminación primaria dependiente de linfocitos y la interferencia de las vías de señalización de citoquinas e interferones, necesarias para el normal desarrollo de la respuesta innata y adaptativa. El desarrollo de vacunas recombinantes que promuevan inmunidad estratégica es uno de los principales desafíos para el control de virus distemper, tanto en poblaciones urbanas como silvestres bajo riesgo de infección (Bronson y col 2007, Rouxel y col 2009). En este contexto, y considerando la inespecificidad de hospedero de VDC, disponer de vacunas seguras de fácil administración y bajo costo que permitan proteger poblaciones silvestres con mínima intervención en el ecosistema y desde edades tempranas, como también generar inmunidad de masa de manera más rápida frente a brotes esporádicos, es un desafío que debe contemplar el uso de vacunas que puedan ser administradas vía oral o intranasal. Aunque para VDC no se han desarrollado vacunas con estas características, se ha demostrado para virus respiratorio sincicial humano, otro miembro de la familia Paramyxoviridae capaz de inhibir la respuesta Th1, que vacunas recombinantes administradas vía intranasal son capaces de estimular una muy buena respuesta tipo Th1 tanto celular como humoral, y con una distribución de sus elementos efectores tanto sistémica como en superficies mucosas (Mok y col 2007). Esta evidencia demuestra que, a pesar de la capacidad que tiene el virus respiratorio sincicial de inhibir la respuesta adaptativa tipo Th1 a nivel de la sinapsis inmunológica (González y col 2008), la vacunación estratégica promueve el desarrollo de una respuesta inmune sólida mientras previene el despliegue de los mecanismos responsables de aquella disrupción y de los procesos inmunopatológicos característicos de la infección.

\section{FUNCIÓN DE CÉLULAS DENDRÍTICAS DURANTE LA INFECCIÓN}

Las células dendríticas (DC) corresponden a presentadoras de antígenos profesionales localizadas de manera ubicua y estratégica para captar antígenos, procesarlos y presentarlos junto a moléculas coestimuladoras (CD80 y CD86) como péptidos asociados a moléculas del complejo principal de histocompatibilidad clase I y II a células T y, de esta forma, promover una adecuada respuesta inmune adaptativa gracias al establecimiento de una sinapsis inmunológica funcional. Se han descrito tres subconjuntos principales de DC; $\mathrm{CD}^{\alpha \alpha+} / \mathrm{CD} 4-, \mathrm{CD} 4+/ \mathrm{CD} 8^{\alpha \alpha-}$ y CD4\% $\mathrm{CD}^{\alpha \alpha-}$ (doble negativas). El primer grupo se diferencia de progenitores comunes por estímulo de IFN- $\gamma$ secretado por células NK y posee la capacidad de inducir una respuesta Th1 mediante la secreción de grandes cantidades de IL-12, mientras que las dos últimas son capaces de 
inducir una respuesta Th2, mediante la secreción de IL-4 (Aliberti y col 2003).

Aunque se reconoce la infección de células dendríticas por VDC, poco se sabe acerca de la capacidad de este virus para interferir con el normal funcionamiento de la sinapsis inmunológica (Wünschmann y col 2000). Algunos estudios han demostrado que sarampión, el Morbillivirus filogenéticamente más cercano a VDC, posee la capacidad de infectar células dendríticas y linfocitos durante la formación de sinapsis inmunológica, junto con inducir actividad citotóxica en DC y el agotamiento selectivo de células Th1 a través de apoptosis inducida por el ligando TRIAL (TNF-related apoptosis-inducing ligand) (Servet-Delprat y col 2003). Además, la infección inhibe la secreción de IL-12, la liberación de quimioquinas y el reclutamiento de células Th1, polarizando de esta forma la respuesta hacia Th2 afectando luego la actividad proliferativa de células $\mathrm{T}$ mediante señalización negativa dependiente de contacto con el complejo glicoproteico viral desplegado en la sinapsis inmunológica (Schneider-Schaulies y col 2003, Abt y col 2009). Estos antecedentes indican posibles mecanismos utilizados por VDC para interferir y evitar el desarrollo de una adecuada respuesta inmune adaptativa. Adicionalmente, considerando la capacidad que poseen los Morbillivirus de reconocer CD150/SLAM, es posible que existan mecanismos que perjudiquen la respuesta Th1 mediante la interferencia con eventos de diferenciación y señalización tempranos, en los que la infección de células NK (vía CD150) y la consecuente inhibición de la secreción de IFN- $\gamma$, produzca la supresión de la diferenciación de DC CD8 $\alpha \alpha+$ a partir de precursores comunes, disminuyendo la inducción de linfocitos con fenotipo Th1.

El desarrollo de un cuadro neurológico de base inmunopatológica en fases tardías de la infección, es un fenómeno que sugiere la existencia de mecanismos moleculares aún desconocidos, capaces de interferir con el normal funcionamiento de las DC, elementos celulares responsables de regular respuestas autoinmunes y mantener un estado de tolerancia inmunológica mediante la supresión de células $\mathrm{T}$ autorreactivas $\mathrm{y}$, de esta forma, proteger la estructura y función de órganos vitales (Steinman y col 2003, Iruretagoyena y col 2006). La barrera hematoencefálica (BHE) determina un estado de privilegio inmunológico en SNC, limitando la infiltración de células inflamatorias e inmunes al parénquima. Sin embargo, la infección viral en astrocitos y la sobreexpresión de CD44 y MMP, conducen a su apertura y, consecuentemente, a la llegada de linfocitos Thelper competentes, capaces de promover una inmunidad descontrolada en respuesta al gran acúmulo de citoquinas proinflamatorias presentes en el tejido. De esta manera, durante el transcurso de la enfermedad, el SNC sufre un daño masivo derivado del proceso inflamatorio exagerado, fenómeno que predispone al progreso de la patología gracias a la masiva presentación de antígenos, incluyendo virales y autoantígenos (como PBM) que estimulan un sistema inmune dañado en su capacidad de autorregulación y favorecen el desarrollo de un proceso autoinmune con características de hipersensibilidad retardada.

\section{NUEVAS HERRAMIENTAS TERAPÉUTICAS EN EL CONTEXTO DE LA INMUNOPATOLOGÍA}

Debido a la inexistencia de protocolos terapéuticos estandarizados y más aún, de antivirales específicos, los tratamientos actuales persiguen controlar las infecciones oportunistas y los signos neurológicos desarrollados en el transcurso de la enfermedad. En este sentido, es importante discutir el uso erróneo de interferón gamma recombinante humano (IFN- $\gamma \mathrm{rh}$ ) y vitamina $\mathrm{C}$ en el contexto de la fisiopatología del cuadro neurológico. El IFN- $\gamma$ corresponde a una citoquina con funciones esenciales en la restricción de la replicación y diseminación multisistémica de agentes virales, mientras coordina la actividad de linfocitos Th1 y citotóxicos (Placek y col 2009). En términos de su actividad biológica, su uso debe restringirse a animales expuestos con riesgo de enfermar, ya que sólo es efectivo en etapas tempranas de la infección cuando aún no se ha irrumpido con el normal funcionamiento de la respuesta Th1. Adicionalmente, considerando que el inicio de la enfermedad neurológica sucede en momentos en los que la naturaleza del cuadro patológico se define entre un proceso inducido por la replicación viral y uno determinado por la hiperreactividad del sistema inmune, el uso de esta citoquina en pacientes con signología asociada a daño neurológico es contraproducente debido a que esta citoquina exacerba el daño sobre SNC mediante el estímulo de poblaciones funcionalmente dependientes de IFN- $\gamma$ : linfocitos Th1 $\mathrm{CD}^{+}{ }^{+}$y CD $8{ }^{+}$efectores. Asimismo, para minimizar el daño inicial sobre la mielina (causado principalmente por radicales libres secretados por la microglia), el uso de antioxidantes, vitamina $\mathrm{E}$, vitaminas del complejo B y altas dosis de vitamina A corresponden a medidas terapéuticas esenciales, en las que debe restringirse el uso de vitamina $\mathrm{C}$ por su capacidad de promover daño inmunomediado al potenciar la respuesta Th1 durante la activación de células T (Noh y col 2005), suceso que en el caso de distemper canino ocurre después de los 21 días PI, momento en el que se está incubando silenciosamente la encefalopatía inmunomediada a través de la activación de linfocitos $\mathrm{T}$ autorreactivos. De esta forma, a diferencia de la vitamina A, que es capaz de disminuir la severidad del cuadro clínico y aumentar la sobrevida de hurones infectados experimentalmente (Rodeheffer y col 2007) el uso de vitamina $\mathrm{C}$ debe restringirse a los protocolos de vacunación donde favorece el adecuado estímulo, desarrollo y refuerzo de la respuesta antiviral mediada por linfocitos Th1.

El control de la inflamación del tejido nervioso es uno de los puntos más importantes en el tratamiento de pacientes con signología nerviosa; sin embargo, el uso de corticoides es bastante perjudicial por su tendencia a promover influjo de glucosa a un tejido bajo estrés 
oxidativo y por los efectos secundarios del tratamiento crónico. Para resolver este problema existen dos alternativas terapéuticas utilizadas por Iruretagoyena y col (2006) en el tratamiento de encefalomielitis autoinmune experimental (EAE): andrografolido y rosiglitazona, la primera corresponde a una lactona dicíclica dipertenoide obtenida de los extractos de Andrographis paniculada, mientras que la segunda es una tiazolidinediona agonista de PPAR (Peroxisome Proliferator-Activated Receptor); ambas se caracterizan por inhibir $\mathrm{NF}-\kappa \mathrm{B}$, principal responsable de la activación de los genes de citoquinas proinflamatorias que corresponden a los mediadores más importantes del progreso de la enfermedad. El efecto modulador de estos fármacos tiene lugar a nivel de células dendríticas, que al sufrir inhibición de NF- $\mathrm{KB}$, adquieren un fenotipo inmaduro tolerogénico capaz de inducir respuestas moduladoras a través de células $\mathrm{T}$ reguladoras (Treg) (Iruretagoyena y

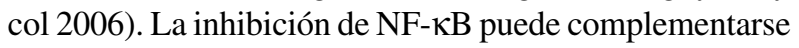
adicionalmente utilizando $\mathrm{N}$-acetil-cisteína (NAC), un antioxidante inmunomodulador cuyo mecanismo de acción incluye la inhibición de la unión al ADN de NF- $\kappa B$, y las consecuentes vías de metabolismo de fosfolipasa $\mathrm{A}_{2}$, la liberación de citoquinas proinflamatorias y la actividad de metaloproteinasas, junto con disminuir la expresión de ICAM-1 (Sakurada y col 1996, Lappas y col 2003). Este hallazgo fue corroborado a nivel de sinapsis inmunológica mediante pruebas de reacción mixta linfocitaria, donde se demuestra la inhibición de la activación de células $\mathrm{T}$ vírgenes de manera dependiente de la presencia de DC tratadas con NAC, sin afectar este compuesto, la viabilidad de las células presentadoras de antígeno ni la activación de células T en ausencia de DC (Verhasselt y col 1999). Estas drogas representan alternativas terapéuticas que deben ser evaluadas como sustitutos de los glucocorticoides para el tratamiento de la enfermedad neurológica inmunomediada (Lee y Burckart 1998).

La inexistencia de drogas antivirales específicas es un desafío importante en el tratamiento de animales infectados, especialmente considerando la elevada mortalidad del cuadro multisistémico. Actualmente se ha conseguido utilizar dos drogas con efecto antiviral promisorio sobre VDC: azatioprina y ribavirina. La primera ha sido utilizada experimentalmente desde el año 2006 en el tratamiento de esta virosis, y a pesar de haber sido administrada inicialmente con el objetivo de controlar la naturaleza inmunomediada del cuadro neurológico, ha mostrado ser una muy buena alternativa terapéutica, logrando limitar el progreso del cuadro multisistémico, aumentar la sobrevida y disminuir la presentación del cuadro neurológico en 32 pacientes (de un total de 41), entre 4 meses y 2 años de edad, con diagnóstico clínico confirmado por PCR ${ }^{1}$ (Reacción en Cadena de la Polimerasa), midiéndose la respuesta al tratamiento como sobrevida a los 28 días de iniciado el tratamiento, evaluando adicionalmente la presencia/ausencia de secuelas

\footnotetext{
Céspedes, datos no publicados, manuscrito en preparación.
}

como mioclonías, amaurosis o convulsiones recurrentes adquiridas, respectivamente. No obstante, si es utilizada de manera inadecuada produce severas complicaciones como trombocitopenia (en dosis mayores de $1 \mathrm{mg} / \mathrm{kg}$ al día), enterotoxemia e infecciones sistémicas derivadas de bronconeumonías y desequilibrios de la flora intestinal, requiriendo evaluación semanal del recuento de plaquetas y linfocitos, el uso de probióticos y una antibioticoterapia específica. Cabe destacar que debido a su farmacodinamia el efecto antiviral de azatioprina fue cuestionado, sin embargo, Hoover y Striker (2008) demostraron la capacidad de este compuesto de limitar la replicación de otro virus ARN, mediante la inhibición de la polimerasa viral ARN dependiente (RPRD) por el ribósido de 6-metil-mercaptopurina (r6-MMP), uno de los metabolitos biológicamente activos generados durante la degradación de AZA por la enzima tiopurina metiltransferasa (TPMT) hepática.

La segunda droga, al igual que azatioprina, inhibe la síntesis de material genético de virus ARN, poseyendo efecto terapéutico demostrado en las virosis causadas por los virus hepatitis $\mathrm{C}$ humano y sarampión, siendo este último el miembro del género Morbillivirus genéticamente más cercano a VDC. Considerando este último antecedente Elia y col (2008) demuestran el efecto antiviral in vitro de ribavirina sobre VDC, caracterizado por inhibir la replicación viral a muy bajas concentraciones del compuesto activo, medido como una disminución de la cantidad de ARN viral en células VERO infectadas y de la capacidad infectante del virus luego de tres generaciones, fenómeno atribuido por los autores a la extinción de la progenie viral.

Debido a que la infección por VDC es una de las principales causas de morbilidad y letalidad en caninos domésticos, y que la patología asociada corresponde a uno de los mejores modelos no murinos de esclerosis múltiple y sarampión, nuevos ensayos son necesarios para determinar la verdadera capacidad in vitro e in vivo de estos compuestos para inhibir la replicación viral e interferir con los mecanismos responsables de la desregulación de la respuesta inmune, especialmente en el caso de azatioprina, que ha sido utilizada durante años como terapia inmunosupresora.

\section{DISCUSIÓN}

La infección por VDC es una de las principales causas de muerte en caninos domésticos y una de las principales amenazas para la conservación de especies silvestres en peligro de extinción. Debido a su distribución global, el virus representa un desafío mayor para la medicina de pequeños animales y los programas de preservación de especies silvestres. En Chile, aunque existen escasos reportes de infecciones en animales silvestres, ciertamente se reconoce la infección esporádica de zorros endémicos, tanto en zonas rurales con poblaciones establecidas de cánidos domésticos como en poblaciones silvestres más aisladas (Moreira y Stutzin 2005). El riesgo de infección de 
estas poblaciones exige diseñar vacunas seguras, estables y de fácil administración (Ej.: en carnadas) que permitan inmunizar animales en riesgo con mínima intervención del ecosistema. En este contexto, una vacuna ideal debe ser capaz de estimular una respuesta inmune de distribución sérica y de mucosas, capaz de prevenir la enfermedad desde la exposición al patógeno, evitando el desarrollo de inmunosupresión y de cuadros patológicos de elevada letalidad. En Chile existen numerosas especies de cánidos y mustélidos silvestres potencialmente susceptibles a la infección por VDC. Un ejemplo de ello, el zorro chilote (Pseudalopex fulvipes), corresponde a una población verdaderamente única, de distribución limitada y en peligro de extinción que puede ser severamente amenazada por la rápida infectividad y letalidad características de la infección.

Considerando la limitada protección de las vacunas polivalentes y el riesgo de encefalitis posvacunal propia de ellas, es importante desarrollar vacunas recombinantes que puedan proteger animales en peligro de extinción frente a brotes esporádicos, permitiendo erradicar el virus de ecosistemas silvestres en condiciones seguras. Asimismo, prescindir de virus atenuados para vacunar contra VDC es un objetivo que también debe plantearse para prevenir la enfermedad en poblaciones de caninos domésticos, especialmente si se desea aplicar programas de vacunación sobre la base de vacunas recombinantes con el fin de erradicar el virus de zonas geográficas de interés para la preservación de vida silvestre. En este contexto, una vacuna ideal debe ser diseñada sólo para VDC y considerar el polimorfismo genético propio del país o continente donde se desee aplicar programas de vacunación estratégica. Lamentablemente, a la fecha no existen estudios filogenéticos en Chile que permitan desarrollar prototipos de vacuna que consideren las variantes genéticas circulantes en el país, especialmente de los antígenos más conservados entre ellas. Esto último limita a los médicos veterinarios a utilizar vacunas recombinantes diseñadas con material genético de cepas extranjeras, no siendo prototipos adecuados para erradicar la enfermedad.

Para aumentar el poder protectivo de vacunas recombinantes es necesario incluir la función especializada del subconjunto de células dendríticas CD8 $\alpha \alpha^{+} / \mathrm{DEC} 205^{+}$en la inducción de una inmunidad adecuada, estrategia que ya ha sido utilizada para Epstein Barr virus, y que puede ser utilizada para VDC mediante la entrega dirigida de antígenos a esta población celular (Gurer y col 2008).

La relevancia de VDC no sólo se restringe a la conservación de animales silvestres y a la medicina de caninos domésticos, sino que adicionalmente repercute en salud pública. Selby y col (2006) han propuesto el posible rol patológico de este virus en la enfermedad de Paget, patología que produce resorción ósea y que se caracteriza por el aumento de la actividad fagocítica de osteoclastos (macrófagos del tejido óseo). Esta hipótesis se basa en la detección de material genético de VDC en muestras de hueso pagético (Mee y col 1993, Mee y col 1998, Hoyland y col 2003) y por la capacidad del virus para generar patología metafisiaria en perros infectados durante el desarrollo de la enfermedad multisistémica (Baumgärtner y col 1995 a , Baumgärtner y col 1995 ${ }^{\mathrm{b}}$, Mee y col 1995, Mee y col $1995^{b}$ ). Considerando esto último, el estudio de la capacidad antiviral in vivo de azatioprina y ribavirina no sólo debe enfocarse en la resolución de la enfermedad, y la prevención del cuadro neurológico y las secuelas propias de la infección, sino que además debe evaluar si existe efecto terapéutico sobre la patología metafisiaria en caninos infectados y, de esta manera, utilizar esta enfermedad no sólo como modelo de estudio para nuevos tratamientos de esclerosis múltiple, sino que además para la enfermedad de Paget.

Debido al pequeño número de pacientes tratados con azatioprina, las conclusiones obtenidas sólo nos permiten proponer a este fármaco como tratamiento antiviral de uso restringido para los casos más severos que incluyan: infección del tracto respiratorio alto o bajo, piodermas superficiales y gastroenteritis no hemorrágicas, no calificando para el tratamiento aquellos pacientes que carezcan de antibioticoterapia complementaria y que presenten trombocitopenia, gastroenteritis hemorrágica o anemia moderada a severa. La búsqueda de un antiviral más seguro es uno de los desafíos más importantes en el diseño de protocolos terapéuticos capaces de limitar la infección y el compromiso de SNC. En este sentido, debido a su efecto antiviral demostrado para diversos virus humanos como hepatitis C, sarampión y VRS, los dos últimos, pertenecientes a la familia Paramyxoviridae, uno de los mejores candidatos corresponde a ribavirina, sin embargo es de limitado acceso para los médicos veterinarios y sus propiedades farmacocinéticas son desconocidas en Canis familiaris.

Luego del establecimiento de la viremia secundaria, una de las consecuencias más importantes es el compromiso de SNC, fenómeno explicado inicialmente por la interrupción de funciones celulares esenciales en oligodendrocitos, astrocitos y la microglia, gracias a fenómenos derivados de la replicación viral diferencial en estas poblaciones celulares. El establecimiento de una infección latente promueve un cuadro inflamatorio inmunomediado con poblaciones autorreactivas de linfocitos, cuyo origen se debe a alteraciones en los procesos fisiológicos encargados de inhibir el desarrollo de enfermedades autoinmunes. En este sentido, el diseño de propuestas terapéuticas requiere incorporar fármacos capaces de favorecer el rol modulador de las células dendríticas sobre la respuesta inmune patológica, específicamente sobre las poblaciones autorreactivas de linfocitos desplegadas en el tejido enfermo. Esta aproximación terapéutica no sólo debe incorporar inhibidores de NF- $\mathrm{\kappa B}$ como sustitutos de glucocorticoides, sino que, además, un manejo nutricional acorde con el estado inmunológico del paciente. Debido a que uno de los principales fenómenos involucrados en la inducción 
del daño en SNC es la secreción local de citoquinas proinflamatorias: andrografolido, rosiglitazona y NAC, representan buenas alternativas terapéuticas a incorporar en el tratamiento de pacientes con encefalopatía. La inhibición a distintos niveles de NF- $\mathrm{KB}$ por parte de estos compuestos permitiría que las células dendríticas presentes en SNC adquieran un fenotipo inmaduro capaz de inducir células $\mathrm{T}$ reguladoras (Treg) y al mismo tiempo inhibir la secreción de citoquinas proinflamatorias por la microglia y otras poblaciones celulares infectadas.

Aunque para distemper aún no se han descrito las características fenotípicas de las poblaciones celulares responsables del daño citotóxico, es bastante probable que, al igual que para esclerosis múltiple, exista un subconjunto de linfocitos $\mathrm{CD}^{+}$tanto $\alpha \beta$ como $\gamma \delta$ seleccionados y activados durante la presentación antigénica junto a linfocitos helper Th1 o Th17. Al considerar esto último, cabe destacar que, aunque el efecto terapéutico de vitamina A en animales infectados es desconocido, en estos últimos años se ha demostrado que el ácido retinoico, sintetizado a partir de retinol por DCs (Yokota y col 2009) posee un rol importante en la adquisición de un fenotipo regulador de células T en EAE, una patología autoinmune asociada por varios autores a una respuesta patológica tipo Th17 (Herrada y col 2010). Este fenómeno no sólo se observa en SNC, pues en patologías inflamatorias de sistema digestivo, caracterizadas por una respuesta patológica tipo Th17, también se ha demostrado el rol tolerogénico que cumplen DC en el homing de linfocitos Treg al intestino enfermo (von Boehmer 2007). Dicha función es llevada a cabo mediante la secreción de TGF- $\beta$ y ácido retinoico en la sinapsis inmunológica entre la DC y un linfocito T regulador. Adicionalmente, el ácido retinoico se ha demostrado capaz de generar de novo e in vitro Treg $\mathrm{CD}^{+} / \mathrm{CD} 25^{+} / \mathrm{FOXP}^{+}$, en ausencia de células dendríticas (Wang y col 2009) e incluso de manera independiente a las citoquinas secretadas durante el establecimiento de la sinapsis inmunológica (Nolting y col 2009). El rol del ácido retinoico se encuentra bien caracterizado para EAE, siendo demostrado incluso en pacientes con esclerosis múltiple (Racke y col 1995, Xiang y col 1998), abriendo la posibilidad de utilizar vitamina A o ácido retinoico con el objetivo de potenciar el desarrollo de tolerancia en esquemas terapéuticos combinados que utilicen inhibidores de NF- $\kappa \mathrm{B}$ (figura 2).

Para conseguir una combinación de fármacos que se adapte de la mejor manera posible a la fisiología y cuadro patológico del animal infectado es necesario considerar los efectos secundarios de la terapia combinada y, en este sentido, el uso crónico de rosiglitazona en altas dosis se ha asociado a un aumento del volumen plasmático y a la generación de hipertrofia concéntrica del corazón. En este último caso, una de las drogas que mejor se adecua a protocolos combinados es espironolactona, cuya farmacodinamia no sólo se restringe a controlar el volumen plasmático sino que además posee la capacidad de inhibir respuestas inmunes patológicas del tipo Th17 (Herrada y col 2010). Este efecto fue demostrado tanto en ensayos in vitro -en los que la administración de esta molécula inhibe la secreción de citoquinas y la expresión de marcadores de superficie asociados a la activación de linfocitos Th 17como en ensayos in vivo, en los que ratones tratados con espironolactona muestran una disminución en la progresión patológica de EAE (Herrada y col 2010).

Pese a que distemper canino es un virus ubiquo cuya infección es de elevada morbilidad y letalidad, a más de 100 años de su descubrimiento aún no existe un tratamiento estandarizado que permita aumentar la sobrevida de los animales enfermos en ausencia de secuelas severas. Nuestro esfuerzo debe considerar el diseño de un protocolo terapéutico para animales enfermos que evalúe el efecto terapéutico combinado de vitaminas (A, E y complejo B, en ausencia de ácido ascórbico), antibióticos, probióticos, inhibidores de NF- $\kappa \mathrm{B}$ o bloqueantes de su unión a ADN en asociación a un antiviral (azatioprina o ribavirina). Dicha evaluación no sólo requiere considerar e incluir variables como género, edad y raza, sino que además los tiempos críticos de intervención durante la evolución de la patología (figura 2), siendo los más importantes el inicio de la ventana de inmunosupresión y la génesis del cuadro inmunomediado en SNC. Aunque el rol de las células dendríticas en el contexto de la inmunopatología de SNC no se conoce del todo para virus distemper en Canis familiaris, existe abundante información sobre el rol de este subconjunto celular en diversas patologías infecciosas e inmunomediadas experimentales desarrolladas en el modelo Mus musculus. Dichas enfermedades han sido herramientas significativas en la evaluación de nuevos tratamientos dirigidos a modular la fisiología de la célula dendrítica y la respuesta inmune a nivel de la sinapsis inmunológica. Sin embargo, mientras no se pueda demostrar dicho efecto modulador sobre las células dendríticas caninas in vitro, el efecto terapéutico de la combinación terapéutica propuesta en esta revisión se limita a la evaluación in vivo de pacientes naturalmente infectados. Esta restricción se explica, en parte, al limitado conocimiento del comportamiento, distribución y funcionalidad de las diversas subpoblaciones de células dendríticas en caninos domésticos, siendo un área de la inmunología veterinaria poco abordada en la actualidad, pese a que los modelos caninos de enfermedad autoinmune espontánea (no experimental), como la enfermedad inflamatoria intestinal (IBD, Inflamatory Bowel Disease) y la encefalopatía causada por VDC recapitulan muchos de los eventos desplegados durante la fisiopatología de la enfermedad de Crohn y esclerosis múltiple, respectivamente.

Al combinar eventos de naturaleza infecciosa e inmunomediada que afectan la funcionalidad de las células dendríticas a nivel de sinapsis inmunológica, tanto en la inhibición selectiva de la subpoblación de linfocitos Th1 como en la génesis de una respuesta inmune exagerada Th1 o Th17, la infección por virus distemper canino representa uno de los mejores modelos de estudio para 


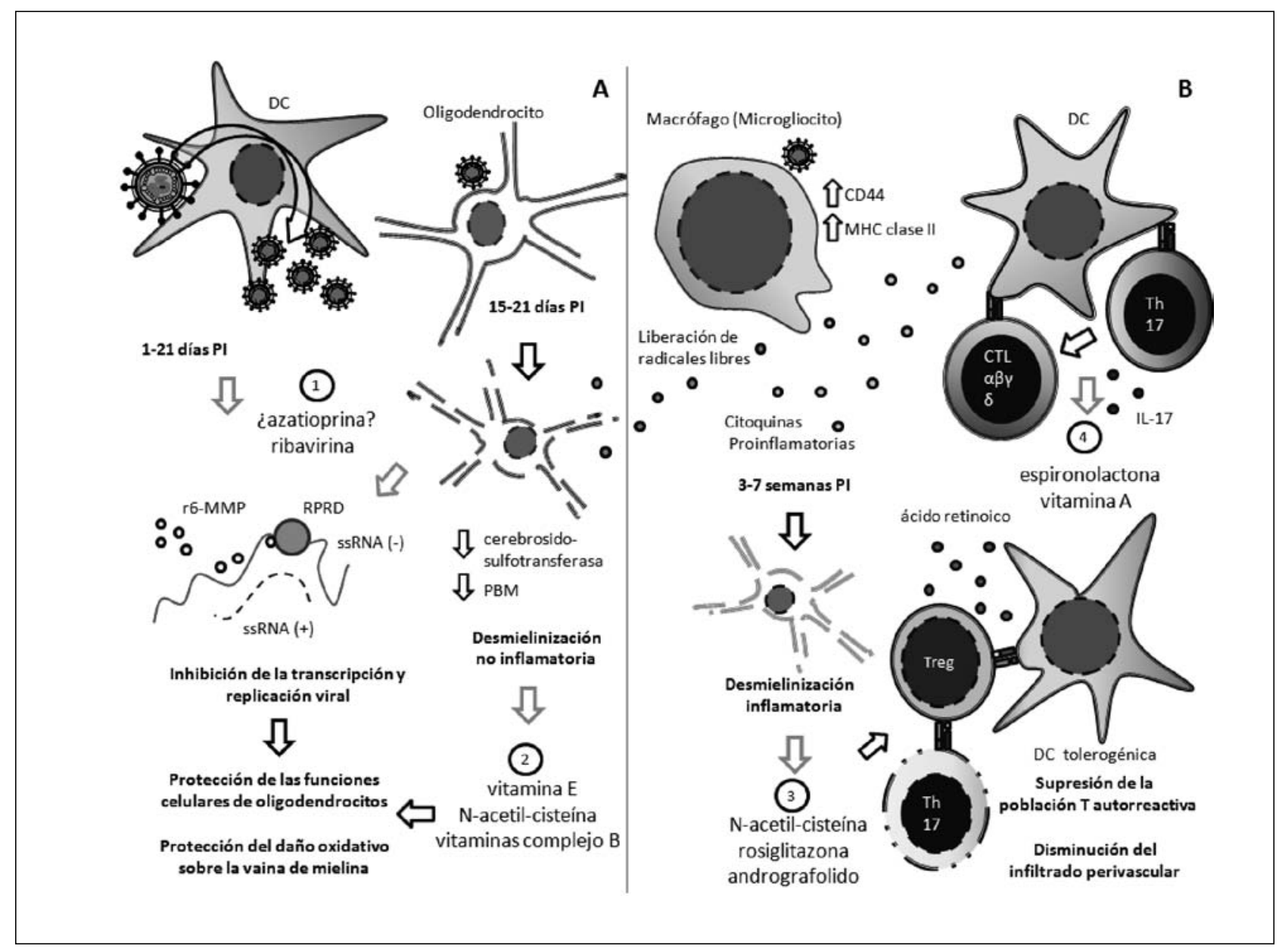

Figura 2. Puntos clave propuestos para la terapia combinada en el curso de la enfermedad neurológica. Eventos secuenciales responsables de la desmielinización observada en pacientes infectados. A) 1-21 días PI, el uso de antivirales (1) se orienta a limitar la infección de células del sistema inmune y la infección restrictiva de oligodendrocitos, microglia y astrocitos. Este último fenómeno determina la inducción de un proceso desmielinizante no inflamatorio (15-21 días PI) caracterizado por la activación de células fagocíticas que liberan radicales libres y, la subexpresión de la proteína básica de mielina y la cerebrósido-sulfotransferasa en oligodendrocitos. Los antioxidantes y vitaminas (2) sirven de neuroprotectores. B) 3 a 7 semanas PI, la infección crónica de VDC en astrocitos y macrófagos producen la sobreexpresión de MHC clase II y citoquinas proinflamatorias, fenómenos que luego de la recuperación de la respuesta inmune predisponen a un cuadro autoinmune dirigido por linfocitos autorreactivos. Debido al rol inflamatorio preponderante de las citoquinas, la inhibición de NF- $\mathrm{KB}$ (3) se orienta a modular la respuesta inmune mediante la supresión de interleuquinas y linfoquinas, y la inducción de un fenotipo tolerogénico en DC. (4) Aunque se desconocen los fenotipos involucrados en el daño citotóxico, el uso de espironolactona y vitamina A permitiría atenuar los efectos secundarios de rosiglitazona y controlar la población autorreactiva $T \gamma \delta$ o T $\alpha \beta$ a través de la inducción de Treg.

Proposed key points for combined therapy in the neurologic disease course. Sequential events responsible for observed demyelinating disease in infected patients. A) 1 to 21 days PI, use of antivirals (1) is directed to limit replication in immune cells, microglia, astrocytes and restrictive-infected oligodendrocytes. This latter phenomenon induce a non-inflammatory demyelinating process (15-21 days PI) characterized by secretion of oxygen reactive species by activated phagocytes as well as myelin basic protein and cerebroside sulfotransferase down-regulation in infected oligodendrocytes. Antioxidants and vitamins (2) serve as protectors of nervous tissue. B) 3 to 7 weeks PI, chronic infection in astrocytes and macrophages induce upregulation of class II MHC and pro-inflammatory cytokines, which after immune response recovery predispose to autoimmune disease mediated by auto-reactive lymphocytes. Inhibition of NF- $\mathrm{KB}(3)$ is directed to modulate immune response through pro-inflammatory cytokines, interleukins and lymphokines suppression and, tolerogenic phenotype induction in DC. (4) Although T lymphocyte phenotypes involved in cytotoxic damage over CNS are unknown, the use of spironolactone and vitamin A will allow diminish secondary effects of rosiglitazone, and at the same time control auto-reactive $\mathrm{T} \gamma \delta$ or $\mathrm{T} \alpha \beta$ cell subsets through Treg induction in nervous tissue.

nuevas alternativas terapéuticas. La validación de un protocolo para el tratamiento de VDC debe considerar la fisiología de las células dendríticas y el uso adecuado de cada uno de los fármacos durante el curso de la infección. Para cumplir con dichos objetivos es necesario estandarizar la terapia combinada de manera tal que permita controlar las diferentes manifestaciones de la infección, una meta que sólo puede ser conseguida con el estudio de pacientes espontáneamente infectados y bajo un seguimiento estricto de cada medida terapéutica adoptada, que permita evaluar de manera objetiva los resultados obtenidos en el contexto de la inmunosupresión y la modulación de la respuesta inmune exagerada y sus secuelas en SNC. 


\section{RESUMEN}

La infección por virus distemper canino (VDC) es la principal causa infecciosa de muerte en caninos domésticos y especies exóticas alrededor del mundo, amenazando especies protegidas como el panda gigante y grandes félidos. A través de la infección de linfocitos y células mononucleares periféricas, VDC bloquea la síntesis y vías de señalización de interferones y citoquinas, fenómeno que produce agotamiento selectivo de linfocitos $\mathrm{CD} 4^{+} \mathrm{Th} 1$ y disminuye la proliferación de células B y T. Estos eventos explican la severa inmunosupresión que caracteriza la infección por VDC y que conduce a una enfermedad multisistémica asociada a infecciones oportunistas deletéreas. Durante el curso de la infección, complejos eventos como la disfunción celular causada directamente por el virus o la respuesta immune exagerada contribuyen a la inmunopatogénesis de SNC. Considerando que varias especies son afectadas y que la infección posee una elevada infectividad y letalidad, esta revisión destaca la importancia de diseñar vacunas más seguras, capaces de inducir una inmunidad estratégica y de prevenir la neuropatología. Adicionalmente, para comprender de mejor manera los diversos y dinámicos mecanismos involucrados en la disrupción de la respuesta immune adaptativa, así como aquellos responsables de la inducción de inmunidad durante la vacunación o la exposición al virus, esta revisión expone el rol de las células dendríticas durante la infección por VDC. Finalmente, se discute cómo las terapias combinadas basadas en la fisiología de estas células nos permitirán mejorar la recuperación de pacientes en términos de sobrevida y la prevención de las secuelas asociadas a la infección.

\section{REFERENCIAS}

Abt M, E Gassert, S Schneider-Schaulies. 2009. Measles virus modulates chemokine release and chemotactic responses of dendritic cells. $J$ Gen Virol 90, 909-914.

Aliberti J, O Schulz, D Pennington, H Tsujimura, C Reis e Sousa, K Ozato, A Sher. 2003. Essential role for ICSBP in the in vivo development of murine CD8+ dendritic cells. Blood 101, 305-310.

Alldinger S, W Baumgärtner, C Örvell. 1993. Restricted expression of viral surface proteins in canine distemper encephalitis. Acta Neuropathol 85, 635-645.

Alldinger S, A Wünschmann, W Baumgärtner, C Voss, E Kremmer. 1996. Up-regulation of major histocompatibility complex class II antigen expression in the central nervous system of dogs with spontaneous canine distemper virus encephalitis. Acta Neuropathol 92, 273-280

Alldinger S, S Gröters, Q Miao, S Fonfara, E Kremmer, W Baumgärtner. 2006. Roles of an extracellular matrix (ECM) receptor and ECM processing enzymes in demyelinating canine distemper encephalitis. Dtsch Tierarztl Wochenschr 113, 151-156.

Baumgärtner W, C Örvell, M Reinacher. 1989. Naturally occurring canine distemper virus encephalitis: distribution and expression of viral polypeptides in nervous tissues. Acta Neuropathol 78, 504-512.

Baumgärtner W, RW Boyce, S Alldinger, MK Axthelm, SE Weisbrode, S Krakowka, K Gaedke. 1995ª Metaphyseal bone lesions in young dogs with systemic canine distemper virus infection. Vet Microbiol 44, 201-209.

Baumgärtner W, RW Boyce, SE Weisbrode, S Alldinger, MK Axthelm, S Krakowka. $1995^{\mathrm{b}}$. Histologic and immunocytochemical characterization of canine distemper-associated metaphyseal bone lesions in young dogs following experimental infection. Vet Pathol 32, 702-709.

Beineke A, S Markus, J Borlak, T Thum, W Baumgärtner. 2008. Increase of pro-inflammatory cytokine expression in non-demyelinating early cerebral lesions in nervous canine distemper. Viral Immunol $21,401-410$.

Beineke A, C Puff, F Seehusen, W Baumgärtner. 2009. Pathogenesis and immunopathology of systemic and nervous canine Distemper. Vet Immunol Immunopathol 127, 1-18.
Bonami F, P Rudd, V von Messling. 2007. Disease duration determines canine distemper virus neurovirulence. J Virology 81, 1206612070.

Bronson E, SL Deem, C Sanchez, S Murray. 2007. Serologic response to a canarypox-vectored canine distemper virus vaccine in the giant panda (Ailuropoda melanoleuca). J Zoo Wildl Med 38, 363-366.

Calderon MG, P Remorini, O Periolo, M Iglesias, N Mattion, J La Torre. 2007. Detection by RT-PCR and genetic characterization of canine distemper virus from vaccinated and non-vaccinated dogs in Argentina. Vet Microbiol 125, 341-349.

Cocks BG, C-CJ Chang, JM Carballido, H Yssel, JE de Vries, G Aversa. 1995. A novel receptor involved in T-cell activation. Nature 376 , 260-263.

Curran J, D Kolakofsky. 2000. Replication of paramyxoviruses. Adv Virus Res 54, 403-422.

Elia G, C Belloli, F Cirone, MS Lucente, M Caruso, V Martella, N Decaro, C Buonavoglia, P Ormas. 2008. In vitro efficacy of ribavirin against canine distemper virus. Antiviral Res 77, 108-113.

Frisk AL, W Baumgärtner, A Gröne. 1999. Dominating interleukin-10 mRNA expression induction in cerebrospinal fluid cells of dogs with natural canine distemper virus induced demyelinating and nondemyelinating CNS lesions. J Neuroimmunol 97, 102-109.

González PA, CE Prado, ED Leiva, LJ Carreño, SM Bueno, CA Riedel, AM Kalergis. 2008. Respiratory syncytial virus impairs T cell activation by preventing synapse assembly with dendritic cells. $P$ Natl Acad Sci 105, 14999-15004.

Gröne A, S Fonfara, W Baumgärtner. 2002. Cell type-dependent cytokine expression after canine Distemper virus infection. Viral Immunol $15,493-505$.

Gurer C, T Strowig, F Brilot, M Pack, C Trumpfheller, F Arrey, CH Gyu Park, R Steinman, C Münz. 2008. Targeting the nuclear antigen 1 of Epstein-Barr virus to the human endocytic receptor DEC-205 stimulates protective T-cell responses. Blood 112, 1231-1239.

Herrada A, F Contreras, N Marini, C Amador, P González, C Cortés, C Riedel, C Carvajal, F Figueroa, L Michea, C Fardella, A Kalergis. 2010. Aldosterone promotes autoimmune damage by enhancing Th17-mediated immunity. J Immunol 184, 191 -202.

Hirama K, Y Goto, M Uema, Y Endo, R Miura, C Kai. 2004. Phylogenetic analysis of the hemagglutinin $(\mathrm{H})$ gene of canine distemper viruses isolated from wild Masked Palm Civets (Paguma larvata). J Vet Med Sci 66, 1575-1578.

Hoover S, R Striker. 2008. Thiopurines inhibit bovine viral diarrhea virus production in a thiopurine methyltransferase-dependent manner. $J$ Gen Virol 89, 1000-1009.

Hoyland JA, JA Dixon, JL Berry, M Davies, PL Selby, AP Mee. 2003. A comparison of in situ hybridisation, reverse transcriptase-polymerase chain reaction (RT-PCR) and in situ-RT-PCR for the detection of canine distemper virus RNA in Paget's disease. J Virol Methods 109, 253-259.

Iruretagoyena M, S Sepúlveda, JP Lezana, M Hermoso, M Bronfman, M Gutiérrez, S Jacobelli, A Kalergis. 2006. Inhibition of Nuclear Factor- $\kappa \mathrm{B}$ enhances the capacity of immature dendritic cells to induce antigen-specific tolerance in experimental autoimmune encephalomyelitis. J Pharmacol Exp Ther 318, 59-67.

Kerdiles YM, B Cherif, JC Marie, N Tremillon, B Blanquier, G Libeau, A Diallo, TF Wild, MB Villiers, B Horvat. 2006. Immunomodulatory properties of morbillivirus nucleoproteins. Viral Immunol 19, 324-334.

Krakowka S, MK Axthelm, GC Johnsen. 1985. Canine Distemper virus. In: Olsen RG, Krakowka S, Blakeslee JR (eds). Comparative pathobiology of viral diseases. Vol 2. CRC Press Inc, Boca Ratón, Florida, USA, Pp 137-164.

Lampert PW. 1978. Autoimmune and virus-induced demyelinating diseases. A review. Am J Pathos 91, 176-208.

Lan NT, R Yamaguchi, A Inomata, Y Furuya, K Uchida, S Sugano, S Tateyama. 2005. Comparative analyses of canine distemper viral isolates from clinical cases of canine Distemper in vaccinated dogs. Vet Microbiol 115, 32-42. 
Lappas M, M Permezel, GE Rice. 2003. N-acetyl-cysteine inhibits phospholipid metabolism, proinflammatory cytokine release, protease activity, and Nuclear Factor- $\mathrm{\kappa B}$ deoxyribonucleic acid-binding activity in human fetal membranes in vitro. J Clin Endocrinol Metab 88, 1723-1729.

Larson LJ, RD Schultz. 2006. Effect of vaccination with recombinant canine distemper virus vaccine immediately before exposure under shelter-like conditions. Vet Ther 7, 113-118.

Larson LJ, RD Schultz. 2007. Three years duration of immunity in dogs vaccinated with a canarypox-vectored recombinant canine distemper virus vaccine. Vet Ther 8, 101-106.

Lee J-I, GJ Burckart. 1998. Nuclear factor kappa B: important transcription factor and therapeutic target. J Clin Pharmacol 38, 981-993.

Markus S, K Failing, W Baumgärtner. 2002. Increased expression of pro-inflammatory cytokines and lack of up-regulation of anti-inflammatory cytokines in early distemper CNS lesions. $J$ Neuroimmunol 125, 30-41.

Martella V, A Pratelli, F Cirone, N Zizzo, N Decaro, A Tinelli, M Foti, C Buonavoglia. 2002. Detection and genetic characterization of canine distemper virus (CDV) from free-ranging red foxes in Italy. Mol Cell Probe 16, 77-83.

Martella V, F Cirone, G Elia, E Lorusso, N Decaro, M Campolo, C Desario, MS Lucente, AL Bellacicco, M Blixenkrone-Møller, LE Carmichael, C Buonavoglia. 2006. Heterogeneity within the hemagglutinin genes of canine distemper virus (CDV) strains detected in Italy. Vet Microbiol 116, 301-309.

Mee AP, PT Sharpe. 1993. Dogs, distemper and Paget's disease. Bioessays 15, 783-789.

Mee AP, C May, D Bennett, PT Sharpe. 1995'. Generation of multinucleated osteoclast-like cells from canine bone marrow: effects of canine distemper virus. Bone 17, 47-55.

Mee AP, JA Hoyland, P Baird, D Bennett, PT Sharpe. 1995 b Canine bone marrow cell cultures infected with canine distemper virus: an in vitro model of Paget's disease. Bone 17, 461S-466S.

Mee AP, JA Dixon, JA Hoyland, M Davies, PL Selby, EB Mawer. 1998. Detection of canine distemper virus in 100\% of Paget's disease samples by in situ-reverse transcriptase-polymerase chain reaction. Bone 23, 171-175.

Miao Q, W Baumgärtner, K Failing, S Alldinger. 2003. Phase-dependent expression of matrix metalloproteinases and their inhibitors in demyelinating canine distemper encephalitis. Acta neuropathol 106, 486-494.

Mochizuki M, M Hashimoto, S Hagiwara, Y Yoshida, S Ishiguro. 1999. Genotypes of canine distemper virus determined by analysis of the hemagglutinin genes of recent isolates from dogs in Japan. J Clin Microbiol 37, 2936-2942.

Mok H, S Lee, TJ Utley, BE Shepherd, VV Polosukhin, ML Collier, NL Davis, RE Johnston, JE Crowe Jr. 2007. Venezuelan equine encephalitis virus replicon particles encoding respiratory syncytial virus surface glycoproteins induce protective mucosal responses in mice and cotton rats. J Virol 81, 13710-13722.

Moreira R, M Stutzin. 2005. Estudio de la mortalidad de zorros en la IV Región. Boletín Veterinario Oficial. SAG, Chile N ${ }^{\circ} 3,1-8$.

Moro L, AS Martins, CM Alves, FG Santos, HL Del Puerto, AC Vasconcelos. 2003. Apoptosis in the cerebellum of dogs with distemper. $J$ Vet Med B 50, 221-225.

Müller CF, RS Fatzer, K Beck, M Vandevelde, A Zurbriggen. 1995. Studies on canine distemper virus persistence in the central nervous system. Acta Neuropathol 89, 438-445.

Noh K, H Lim, S-K Moon, JS Kang, WJ Lee, D Lee, Y-I Hwang. 2005. Mega-dose Vitamin C modulates T cell functions in Balb/c mice only when administered during $\mathrm{T}$ cell activation. Immunol Lett 98 , 63-72.

Nolting J, C Daniel, S Reuter, C Stuelten, P Li, H Sucov, B-G Kim, JJ Letterio, K Kretschmer, H-J Kim, H von Boehmer. 2009. Retinoic acid can enhance conversion of naive into regulatory $\mathrm{T}$ cells independently of secreted cytokines. J Exp Med 206, 2131-2139.
Orlando EA, I Imbschweiler, I Gerhauser, W Baumgärtner, K Wewetzer. 2008. In vitro characterization and preferential infection by canine distemper virus of glial precursors with Schwann cell characteristics from adult canine brain. Neuropathol Appl Neurobiol 34, 621-637.

Pardo IDR, GC Johnson, SB Kleiboeker. 2005. Phylogenetic characterization of canine distemper viruses detected in naturally infected dogs in North America. J Clin Microbiol 43, 5009-5017.

Pardo MC, P Tanner, J Bauman, K Silver, L Fischer. 2007. Immunization of puppies in the presence of maternally derived antibodies against canine distemper virus. J Comp Pathol 137, 72S-75S.

Pillet S, V von Messling. 2009. Canine distemper virus selectively inhibits apoptosis progression in infected immune cells. J Virol 12, 6279-6287.

Placek K, M Coffre, S Maiella, E Bianchi, L Rogge. 2009. Genetic and epigenetic networks controlling $\mathrm{T}$ helper 1 cell differentiation. Immunology 127, 155-162.

Racke MK, D Burnett, S-H Pak, PS Albert, B Cannella, CS Raine, DE McFarlin, DE Scotts. 1995. Retinoid treatment of experimental allergic encephalomyelitis: il-4 production correlates with improved disease course. J Immunol 154, 450-458.

Rodeheffer C, V von Messling, S Milot, F Lepine, AR Manges, BJ Ward. 2007. Disease manifestations of canine distemper virus infection in ferrets are modulated by vitamin A status. J Nutr 137, 1916-1922.

Rouxel RN, N Svitek, V von Messling. 2009. A chimeric measles virus with canine distemper envelope protects ferrets from lethal distemper challenge. Vaccine 27, 4961-4966.

Rudd P, R Cattaneo, V von Messling. 2006. Canine Distemper virus uses both the anterograde and the hematogenous pathway for neuroinvasion. J Virol 80, 9361-9370.

Sakurada S, T Kato, T Okamoto. 1996. Induction of cytokines and ICAM-1 by proinflammatory cytokines in primary rheumatoid synovial fibroblasts and inhibition by N-acetyl-L-cysteine and aspirin. Int Immunol 8, 1483-1493.

Schneider-Schaulies S, IM Klagge, V ter Meulen. 2003. Dendritic cells and measles virus infection. Curr Top Microbiol Immunol 276, 77-101.

Schobesberger M, A Summerfield, MG Doherr, A Zurbriggen, C Griot. 2005. Canine distemper virus-induced depletion of uninfected lymphocytes is associated with apoptosis. Vet Immunol Immunopathol 104, 33-44.

Selby PL, M Davies, AP Mee. 2006. Canine distemper virus induces human osteoclastogenesis through NF-kappaB and sequestosome 1/P62 activation. J Bone Miner Res 21, 1750-1756.

Sereda AD, KE Gavrilov, LG Fugina. 1999. Distemper of carnivore: proliferative activity of lymphocytes in sick and vaccinated dogs. Vopr Virusol 44, 257-261.

Servet-Delprat C, PO Vidalain, H Valentin, C Rabourdin-Combe. 2003. Measles virus and dendritic cell functions: how specific response cohabits with immunosuppression. Curr Top Microbiol Immunol 276, 103-123.

Sidhu MS, W Husar, SD Cook, PC Dowling, SA Udem. 1993. Canine distemper terminal and intergenic non-protein coding nucleotide sequences: completion of the entire CDV genome sequence. Virology 193, 66-72.

Sidorenko SP, EA Clark. 2003. The dual-function CD150 receptor subfamily: the viral attraction. Nat Immunol 4, 19-24.

Steinman RM, D Hawiger, MC Nussenzweig. 2003. Tolerogenic dendritic cells. Аппи Rev Immunol 21, 685-711.

Strasser A, B May, A Teltscher, E Wistrela, H Niedermüller. 2003. Immune modulation following immunization with polyvalent vaccines in dogs. Vet Immunol Immunopathol 94, 113-121.

Summers BA, MJ Appel. 1994. Aspects of canine distemper virus and measles virus encephalomyelitis. Neuropathol Appl Neurobiol 20, 525-534.

Suter SE, MB Chein, V von Messling, B Yip, R Cattaneo, W Vernau, BR Madewell, CA London. 2005. In vitro canine distemper virus 
infection of canine lymphoid cells: a prelude to oncolytic therapy for lymphoma. Clin Cancer Res 11, 1579-1587.

Tatsuo H, N Ono, Y Yanagi. 2001. Morvilliviruses use signaling lymphocyte activation molecules (CD150) as cellular receptors. $J$ Virol 75, 5842-5850.

Tipold A, Moore P, A Zurbriggen, I Burgener, G Barben, M Vandevelde. 1999. Early T cell response in the central nervous system in canine distemper virus infection. Acta Neuropathol 97, 45-56.

Tipold A, M Vandevelde, R Wittek, P Moore, A Summerfield, A Zurbriggen. 2001. Partial protection and intrathecal invasion of CD8+T cells in acute canine distemper virus infection. Vet Microbiol 83, 189-203.

Uema M, K Ohashi, C Wasaka, C Kai. 2004. Phylogenetic and restriction fragment length polymorphism analyses of hemagglutinin $(\mathrm{H})$ protein of canine distemper virus isolates from domestic dogs in Japan. Virus Res 109, 59-63.

Vandevelde M. 2004. The pathogenesis of nervous distemper. Award Lecture, WSAVA/Waltham International Award for Scientific Achievement, WSAVA FECAVA HVMS World Congress Scientific Proceedings. Rhodes, Greece.

Vandevelde M, A Zurbriggen. 2005. Demyelination in canine distemper virus infection: a review. Acta Neuropathol 109, 56-68.

Verhasselt V, WV Berghe, N Vanderheyde, F Willems, G Haegeman, M Goldman. 1999. N-acetyl-L-cysteine inhibits primary human T cell responses at the dendritic cell level: association with $\mathrm{NF}-\kappa \mathrm{B}$ inhibition. J Immunol 162, 2569-2574.

Von Boehmer H. 2007. Oral tolerance: is it all retinoic acid? J Exp Med 204, 1737-1739.

Von Messling V, G Zimmer, G Herrler, L Haas, R Cattaneo. 2001. The hemagglutinin of canine distemper virus determines tropism and cytopathogenicity. J Virol 75, 6418-6427.

Von Messling V, C Springfeld, P Devaux, R Cattaneo. 2003. A ferret model of canine distemper virus virulence and inmunosuppression. J Virol 77, 12579-12591.
Von Messling V, D Milosevic, R Cattaneo. 2004. Tropism illuminated: lymphocyte-based pathways blazed by lethal morbillivirus through the host immune system. P Natl Acad Sci 101, 14216-14221.

Von Messling V, N Oezguen, Q Zheng, S Vongpunsawad, W Braun, R Cattaneo. 2005. Nearby clusters of hemagglutinin residues sustain SLAM-dependent canine distemper virus entry in peripheral blood mononuclear cells. J Virol 79, 5857-5862.

Von Messling V, N Svitek, R Cattaneo. 2006. Receptor (SLAM[CD150]) recognition and the $\mathrm{V}$ protein sustain swift lymphocyte-based invasion of mucosal tissue and lymphatic organs by a morvillivirus. J Virol 80, 6084-6092.

Wang J, TW Huizinga, RE Toes. 2009. De novo generation and enhanced suppression of human CD4+CD25+ regulatory T cells by retinoic acid. J Immunol 183, 4119-4126.

Wünschmann A, S Alldinger, E Kremmer, W Baumgärtner. 1999. Identification of CD4+ and CD8+ T cell subsets and B cells in the brain of dogs with spontaneous acute, subacute-, and chronicdemyelinating distemper encephalitis. Vet Immunol Immunopathol 67, 101-116.

Wünschmann A, E Kremmer, W Baumgärtner. 2000. Phenotypical characterization of $\mathrm{T}$ and $\mathrm{B}$ cell areas in lymphoid tissues of dogs with spontaneous distemper. Vet Immunol Immunopathol 73, 83-98.

Xiang Z, A Dayal, MA Jensen, BGW Arnason. 1998. All-trans retinoic acid potentiates the ability of interferon beta- $1 \mathrm{~b}$ to augment suppressor cell function in Multiple Sclerosis. Arch Neurol 55, 315-321.

Yokota A, H Takeuchi, N Maeda, Y Ohoka, C Kato, S-Y Song, M Iwata. 2009. GM-CSF and IL-4 synergistically trigger dendritic cells to acquire retinoic acid-producing capacity. Int Immunol 21, 361-377.

Zhao J, X Yan, W Wu. 2008. Genetic variations and cellular receptors of canine distemper virus-a review. Wei Sheng Wu Xиe Bao 48, 986-991. 